\title{
Durabilidade de rosas, gérberas e crisântemos comercializados em Pelotas-RS ${ }^{(1)}$
}

\author{
SÍNTIA ZITZKE FISCHER*(2); ELISABETH REGINA TEMPEL STUMPF(2); \\ CAROLINE MARQUES CASTRO(3); ROSA LÍA BARBIERI(3); GUSTAVO HEIDEN ${ }^{(3)}$
}

\begin{abstract}
RESUMO
As flores de corte representam um dos mais importantes produtos da floricultura, sendo a durabilidade uma das características que definem seu padrão de qualidade. Neste sentido, quanto menor a distância entre a área de produção e o mercado consumidor, maior será o período de uso. Com base no exposto, o trabalho foi desenvolvido com o objetivo de comparar a durabilidade em vaso de rosas, gérberas e crisântemos cultivados no município de Pelotas com a durabilidade das mesmas flores fornecidas por atacadistas de São Paulo. Para cada tratamento (procedência) foram avaliadas 20 hastes de cada espécie. O delineamento experimental adotado foi o de blocos completos ao acaso, com cinco repetições de quatro hastes por bloco, com avaliações feitas a cada três dias, durante 15 dias. A durabilidade em vaso foi superior para as rosas e gérberas produzidas em Pelotas, com média de 9 e 7 dias, respectivamente. Para crisântemos não foi observada diferença significativa, com uma durabilidade média de 12 dias para ambas as procedências. Os resultados permitem afirmar que a distância entre as áreas de produção e o mercado consumidor influencia na qualidade e durabilidade em vaso de rosas e de gérberas comercializadas no município de Pelotas.
\end{abstract}

Palavras-chave: flores de corte, longevidade em vaso, produção local, qualidade estética.

\begin{abstract}
Vase life of roses, gerberas and chrysanthemums commercialized in Pelotas-RS

Cut flowers are one of the most important floricultural products and one of the features that define its quality is vase life. Thus, longer vase life will be achieved when production sites are closer to the consumer market. Based on the above, this experiment compared vase life of rose, gerbera and chrysanthemums supplied by Pelotas's local growers and by São Paulo's wholesalers. For each treatment (origin), 20 stems of each species were evaluated. Randomized block design were used with five repetitions of four stems per block and vase life assessment performed every three days during 15 days. Vase life was higher for roses and gerberas produced in Pelotas, average of 9 and 7 days, respectively. No significant difference was observed to chrysanthemum vase life, average were 12 days for both flower origins. The results indicate that the distance between the production sites and the consumer market influences the quality and vase life of roses and gerberas marketed in Pelotas.
\end{abstract}

Keywords: cut flowers, vase life, local production, aesthetic quality.

\section{INTRODUÇÃO}

Afloriculturaéumaatividadeconsolidadanoagronegócio brasileiro, alcançando significativa importância econômica em vários estados. Um dos segmentos que mais se destaca é o de flores de corte, ocupando cerca de $40 \%$ do mercado brasileiro de flores e plantas ornamentais (REETZ, 2007). Esse segmento enfrenta um mercado cada vez mais exigente e competitivo, especialmente com relação ao padrão de qualidade dos produtos, cuja certificação emprega diversos critérios, dentre esses, a durabilidade em vaso (ASGHARI et al., 2014).

Devido à fragilidade e alta perecibilidade das flores de corte, são requeridos cuidados especiais durante todo o processo produtivo, como forma de garantir a qualidade e a durabilidade que o consumidor final busca. Danos significativos são passíveis de acontecer no momento da colheita, durante a embalagem e armazenamento e mesmo durante o transporte. Tsegaw et al. (2011) relatam que, devido a problemas fisiológicos e patológicos causados durante o manejo na pós-colheita, aproximadamente $20 \%$ do total de flores de corte são perdidos durante o transporte. Esse percentual pode ser ainda maior conforme o sistema de transporte utilizado e o tempo demandado para levar os produtos até o mercado. Flores e plantas ornamentais precisam de transporte refrigerado a fim de manter o padrão de qualidade. No entanto, no Brasil, o transporte sem refrigeração é predominante, o que provoca significativa depreciação e perda de produtos (BUAINAIN e BATALHA, 2007). No País, perdas na ordem de 20 a $50 \%$ ocorrem com produtos hortícolas e flores, apenas no trajeto entre as áreas de produção e o consumidor (SEBRAE, 2005). Ainda com relação ao transporte, Reid e Ferrante (2002) ressaltam que o tempo decorrente desde a

\footnotetext{
(1) Trabalho recebido para publicação em 13/08/2014 e aprovado em 04/03/2015

(2) Instituto Federal Sul-Rio-grandense (IFSul), Câmpus Pelotas - Visconde da Graça, Pelotas-RS. *Autor correspondente: sintiafischer@cavg.ifsul.edu.br

(3) Embrapa Clima Temperado, Pelotas-RS
} 
colheita até a comercialização é um dos fatores que devem ser considerados para garantir a durabilidade de flores. Por essa razão, o ideal é que os centros produtores estejam próximos aos locais de consumo, principalmente para reduzir as perdas pelo estresse e injúrias causados durante o transporte.

A crescente exigência dos consumidores por qualidade, durabilidade e frescor, valoriza os produtos cultivados em áreas mais próximas do mercado, propiciando o crescimento e a consolidação de diversos polos de produção de flores e plantas ornamentais em todo o território brasileiro, a exemplo do que ocorreu no Rio Grande do Sul (JUNQUEIRA e PEETZ, 2008).

Pelotas, localizada no sul do RS, é uma das regiões produtoras do estado, abastecendo floriculturas e decoradores do entorno (STUMPF et al., 2007). No entanto, a maior parte das flores e plantas ornamentais comercializadas no município ainda é proveniente do estado de São Paulo e do norte do Rio Grande do Sul, já que o volume da produção local não atende toda a demanda (STUMPF et al., 2005). Stumpf et al. (2008) destacam que um dos maiores problemas que a região enfrenta é a baixa qualidade e durabilidade dos produtos que são entregues pelos fornecedores. Apesar disso, a pressão que os atacadistas exercem sobre seus clientes, aliado à reduzida diversificação e volume da produção local, faz com que muitos compradores se rendam aos produtos vindos de fora. Mesmo assim, algumas floriculturas e decoradores reconhecem as vantagens da produção local e adquirem apenas seus produtos, complementando com os de outras regiões eventualmente, de acordo com a necessidade.

A divulgação de pesquisas que certifiquem o efeito da distância das áreas de produção sobre a qualidade e durabilidade de flores de corte no município de Pelotas poderá fortalecer e atribuir competitividade à floricultura local, alavancando a produção e a comercialização dos seus produtos, como observado por Junqueira e Peetz (2008). Assim sendo, o trabalho foi desenvolvido com o objetivo de comparar a durabilidade em vaso de rosas, gérberas e crisântemos cultivados no município de Pelotas com a durabilidade das mesmas flores fornecidas por atacadistas de São Paulo.

\section{MATERIAL E MÉTODOS}

O experimento foi realizado em laboratório da Embrapa Clima Temperado, em Pelotas, no mês de dezembro de 2013, durante um período de 15 dias. Foram avaliadas rosas da variedade Vegas, gérberas da variedade Dino e crisântemos-margarida da variedade Dark, provenientes de áreas de cultivo localizadas no estado de São Paulo, a cerca de 1.500 km de distância do município, e em Pelotas. As espécies e variedades foram escolhidas em função da produção local. A partir dessa escolha, o atacadista localizou produtores paulistas capazes de fornecer as mesmas variedades. Tanto as flores fornecidas por atacadistas de São Paulo, quanto as fornecidas por produtores de Pelotas, foram adquiridas na mesma data, em uma mesma floricultura do município.

No local do experimento, 20 hastes de cada espécie e de cada local de origem foram uniformizadas em $35 \mathrm{~cm}$ de comprimento, por corte em bisel, com a retirada das folhas do terço basal. Nas rosas foi mantida apenas uma folha com três folíolos em cada haste. Nos crisântemos foram mantidas de duas a seis inflorescências por haste, em diferentes fases de abertura floral, conforme são usualmente comercializados nas floriculturas. As hastes de gérberas não passaram por nenhum tipo de procedimento além da uniformização do comprimento.

Após o preparo, as hastes foram imediatamente acondicionadas em vasos plásticos transparentes, preenchidos com um litro de água de saneamento urbano. A água dos recipientes não foi trocada durante o experimento, no entanto, o volume era complementado a cada três dias, quando eram feitas as avaliações. O uso de ambiente não controlado e de água de saneamento urbano foram adotados para reproduzir os procedimentos empregados pelo consumidor final.

Foi utilizado o delineamento de blocos completos ao acaso, com cinco repetições, nos três experimentos. Cada vaso plástico foi considerado um bloco, com dois tratamentos: produto oriundo de São Paulo e produto proveniente de Pelotas. Foram avaliadas quatro hastes por tratamento, totalizando oito hastes em cada bloco.

Avaliações qualitativas relacionadas ao aspecto estético determinaram o ponto de descarte das flores. Assim, elas foram descartadas ao apresentar amarelecimento de hastes e/ou folhas, perda de turgidez da haste, murcha de flores ou ainda queda de estruturas.

Com base na durabilidade em vaso, considerada pelo número de dias a partir da aquisição na floricultura até a data de descarte total, foi realizada uma análise de variância com o objetivo de testar as diferenças entre os tratamentos, utilizando o procedimento GLM, do pacote estatístico SAS (SAS INSTITUTE INC., 1990). As médias de cada tratamento foram comparadas pelo teste de Tukey a 5\% de probabilidade. Os dados obtidos na análise de variância para rosas e gérberas foram transformados, para atender as pressuposições estatísticas, para $\log 10$ e $1 / \mathrm{x}^{2}(\mathrm{x}=$ número de dias), respectivamente.

\section{RESULTADOS E DISCUSSÃO}

Os resultados apresentados na tabela 1 mostram que houve efeito do tratamento nas três espécies avaliadas. $\mathrm{Na}$ tabela 2 é possível observar que a durabilidade das hastes florais de rosas e gérberas foi superior nas provenientes da produção local em relação às oriundas de São Paulo, enquanto que para as hastes de crisântemo não houve diferença estatística entre os tratamentos. 
Tabela 1. Resumo da análise da variância para a variável durabilidade em vaso, em dias, para rosas, gérberas e crisântemos. Table 1. Analysis of Variance of vase life, in days, for roses, gerberas and chrysanthemums.

\begin{tabular}{|c|c|c|c|c|c|c|c|c|c|c|}
\hline $\begin{array}{c}\text { Fonte de } \\
\text { variação }\end{array}$ & G.L. & \multicolumn{3}{|c|}{ Rosas } & \multicolumn{3}{c|}{ Gérberas } & \multicolumn{3}{c|}{ Crisântemos } \\
\hline Tratamento & 1 & Q.M. & F & P > F & Q.M. & F & P > F & Q.M. & F & P > F \\
\hline Blocos & 4 & 136,58 & 0,0003 & 0,020 & 201,47 & 0,0001 & 1,23 & 7,54 & 0,05 \\
\hline Resíduo & 4 & 0,0024 & 0,97 & 0,51 & 0,00002 & 1,00 & 0,50 & 0,08 & 0,54 & 0,72 \\
\hline C. V. (\%) & & & & 0,00002 & & & 0,16 & \\
\hline
\end{tabular}

G. L.: graus de liberdade; Q. M.: quadrado médio; C. V.: coeficiente de variação.

As rosas produzidas em Pelotas apresentaram uma durabilidade média de 9 dias (Tabela 2), mesmo resultado encontrado por Pietro et al. (2012) em experimento com rosas da mesma variedade, e de acordo com o período médio normalmente verificado para a espécie, que é de 10 dias
(ASGHARI et al., 2014). O primeiro descarte, de apenas uma haste, ocorreu aos 3 dias, por perda de turgidez abaixo do receptáculo floral e por queda de pétalas. As últimas 10 hastes, descartadas apenas ao final do experimento, apresentavam abertura floral plena, com murcha e queda de pétalas.

Tabela 2. Durabilidade em vaso média de hastes florais de rosas, gérberas e crisântemos comercializados em Pelotas, provenientes de São Paulo e da produção local.

Table 2. Average vase life for roses, gerberas and chrysanthemums floral stalks commercialized in Pelotas, produced either locally or in São Paulo.

\begin{tabular}{|c|c|c|}
\hline \multirow{2}{*}{ Espécie } & \multicolumn{2}{|c|}{ Durabilidade (dias) } \\
\cline { 2 - 3 } & Pelotas & São Paulo \\
\hline Rosas & $8,8 \mathrm{a}$ & $3,7 \mathrm{~b}$ \\
\hline Gérberas & $7,2 \mathrm{a}$ & $3,0 \mathrm{~b}$ \\
\hline Crisântemos & $12,9 \mathrm{a}$ & $12,2 \mathrm{a}$ \\
\hline
\end{tabular}

Médias seguidas por letras distintas na linha diferem entre si pelo Teste de Tukey a 5\% de probabilidade.

As rosas oriundas de São Paulo, por sua vez, duraram menos de 4 dias (Tabela 2). O primeiro descarte, de $65 \%$ das hastes (13 hastes), ocorreu aos 3 dias da aquisição, sendo que as demais (35\%) foram descartadas 3 dias após. As flores foram descartadas por perda de turgidez da haste, queda de pétalas e/ou murcha das flores. Vale ressaltar que, neste caso, não ocorreu a antese, ou seja, as flores murcharam sem nem ao menos abrir.

Com relação às gérberas, também as da produção local obtiveram melhor desempenho (Tabela 2). Os resultados mostraram uma durabilidade média de 7 dias, resultado semelhante ao que Reis (2009) obteve para gérberas da variedade Suzane, que foi de pouco mais de 6 dias. Segundo Emongor (2004), gérberas normalmente mantém sua qualidade estética por 7 a 12 dias, concordando com os resultados encontrados nesse experimento.

$\mathrm{O}$ primeiro descarte, de três hastes das gérberas cultivadas em Pelotas, foi feito aos 3 dias, por perda de turgidez da haste, causando uma curvatura acentuada, ainda que as inflorescências estivessem com características estéticas apropriadas. Ao final de 15 dias, $35 \%$ das hastes ainda mostravam plenas condições de uso.

As gérberas produzidas em São Paulo apresentavam, já no momento da aquisição, flores manchadas e com marcas de danos mecânicos, provavelmente causados pela prática de carga e descarga das plantas durante o transporte e entrega nos pontos intermediários. Esta falta de cuidados pode provocar lesões nos tecidos, contribuindo para a infecção por patógenos, ou causar manchas nas pétalas e quebra de hastes ou folhas, prejudicando o aspecto estético das flores, reduzindo desta forma, a sua durabilidade. Além disso, apesar de serem da mesma variedade das flores fornecidas pelo produtor de Pelotas, foi possível observar, visualmente, que as gérberas de São Paulo apresentavam menor diâmetro de inflorescência e tonalidade mais clara, possivelmente em decorrência do ambiente ou sistema de cultivo. Todas as 20 hastes foram descartadas aos três dias (Tabela 2), devido à perda total de turgidez das hastes $\mathrm{e}$ início de murcha das inflorescências.

Os crisântemos, tanto os produzidos em Pelotas como em São Paulo, apresentavam sintomas de ferrugem nas folhas desde o momento da aquisição, porém com grau de infestação visivelmente maior nos provenientes de São Paulo. Os crisântemos fornecidos pelos produtores de Pelotas apresentaram uma durabilidade média de 13 dias (Tabela 2), semelhante à durabilidade média de 12 dias que Silva e Silva (2010) encontraram para crisântemos mantidos em água destilada, e dentro da durabilidade normalmente observada para a espécie, que gira em torno de 10 a 14 dias (REID e FERRANTE, 2002). O primeiro 
descarte, de apenas uma haste, foi feito somente aos 11 dias da instalação. Ao final do experimento, $80 \%$ das hastes ainda estavam com condições estéticas adequadas para uso.

Os crisântemos fornecidos pelo atacadista de São Paulo duraram em média 12 dias, não mostrando, portanto, diferença significativa com relação à produção local (Tabela 2). O primeiro descarte, de oito hastes, ocorreu também aos 11 dias do início do experimento. Ao terminar o período experimental, $60 \%$ das hastes ainda permaneciam com qualidade adequada para uso. Entretanto, no momento da instalação do experimento foi observado que 18 das 38 hastes $(47,4 \%)$ contidas no pacote adquirido de São Paulo, não apresentavam qualidade adequada para uso, necessitando serem descartadas. Neste caso, é importante observar que a falta de qualidade do produto interferiu na quantidade de flores aproveitáveis por pacote, o que prejudica diretamente a comercialização, visto que não há ressarcimento do prejuízo.

O descarte dos crisântemos, independente da procedência, ocorreu por perda de turgidez das hastes, por alteração na coloração das flores, por queda de estruturas florais ou quando, no mínimo metade das inflorescências de cada haste, mostrou sinais evidentes de senescência. Embora sem diferença estatística, ao final do experimento os crisântemos da produção local mostravam melhor qualidade estética do que os provenientes de São Paulo, sugerindo que seu período de durabilidade seria superior, o que poderia ser comprovado caso as observações continuassem além dos 15 dias estabelecidos para o experimento.

A diferença na durabilidade das flores avaliadas neste trabalho pode ser creditada ao tempo de transporte e ao sistema de distribuição dos produtos. As flores e plantas produzidas em outros estados geralmente chegam ao atacado gaúcho por via rodoviária. $\mathrm{O}$ transporte a partir de São Paulo, por exemplo, pode durar até 24 horas para chegar aos atacadistas no Rio Grande do Sul (SEBRAE, 2003), para só então ocorrer a distribuição ao varejo, o que pode demorar no mínimo outras 24 horas, reduzindo ainda mais o período de uso das flores pelo consumidor final. Em Pelotas, as áreas de produção estão localizadas a não mais de $40 \mathrm{~km}$ dos locais de comercialização. Os produtores fazem suas entregas, sem intermediários, em geral no mesmo dia da colheita, o que preserva a qualidade e amplia o período de comercialização e uso das flores (STUMPF et al., 2007).

\section{CONCLUSÕES}

A distância entre as áreas de produção e o mercado consumidor influencia na qualidade e durabilidade em vaso de rosas da variedade Vegas e de gérberas da variedade Dino comercializadas no município de Pelotas.

\section{REFERÊNCIAS}

ASGHARI, R.; SALARI, A.; GHAREHDAGHI, S. Effect of pulsing solution and packaging type under exogenous ethylene on physiological characteristics and post harvesting quality of cut roses (Rosa hybrida). AmericanEurasian Journal of Agricultural \& Environmental Sciences, v.14, n.4, p. 329-335, 2014.

BUAINAIN, A.; BATALHA, M.O. Cadeias produtivas de flores e mel. Brasília: IICA: MAPA/SPA, 2007. 140p.

EMONGOR, V.E. Effects of gibberellic acid on postharvest quality and vaselife life of gérbera cut flowers (Gerbera jamensonii). Journal of Agronomy, v.3, n.3, p.191-195, 2004.

JUNQUEIRA, A.H.; PEETZ, M.S. Mercado interno para os produtos da floricultura brasileira: características, tendências e importância socioeconômica recente. Revista Brasileira de Horticultura Ornamental, Campinas, v.14, n.1, p.37-52, 2008.

PIETRO, J.; MATTIUZI, B.; MATTIUZ, C.F.M.; RODRIGUES, T.J.D. Qualidade de rosas de corte tratadas com produtos naturais. Ciência Rural, Santa Maria, v.42, n.10, p.1781-1788, 2012.

REETZ, E.R. Anuário brasileiro das flores 2007. Santa Cruz do Sul: Editora Gazeta Santa Cruz, 2007. 112 p.

REID, M.; FERRANTE, A. Conservazione di fiori e fronde recise: fisiologia e tecnologia postraccolta di prodotti floricoli freschi. Firenze: ARSIA, 2002. 134p.

REIS, S.N. Soluções de pulsing e de manutenção póscolheita de flores de corte. 2009. 73 f. Tese (Doutorado em Fitotecnia) - Faculdade de Agronomia, Universidade Federal de Lavras, 2009.

SAS INSTITUTE INC. User's guide - version 6.04. 4 ed. Cary, SAS Institute Inc., 1990. 1686 p.

SEBRAE. Diagnóstico da cadeia produtiva de flores e plantas ornamentais do Rio Grande do Sul. Porto Alegre: Editora Vangraf, 2003. 159p.

SEBRAE. Pesquisas reduzem desperdício. SEBRAE Agronegócios.2005.Disponívelem: <http://201.2.114.147/ bds/BDS.nsf/F97237DF2663566E032570CB0047765B/\$ File/NT000AD51E.pdf>. Acesso em 28 de julho de 2014.

SILVA, L.R.; SILVA, S.M. Armazenamento de crisântemos brancos sob condição ambiente utilizando soluções conservantes. Semina: Ciências Agrárias, Londrina, v.31, n.1, p.85-92, 2010.

STUMPF, E.R.T.; FISCHER，S.Z.; BARBIERI, R.L.; GARRASTAZU, M.C. O setor produtivo de plantas ornamentais nos Coredes Sul e Centro-Sul do Rio Grande do Sul. Pelotas: Embrapa Clima Temperado, 2005. 26p. 
STUMPF, E.R.T.; FISCHER, S.Z.; BARBIERI, R.L.; HEIDEN, G. Floricultura e Cultivo Comercial de Flores de Corte no Rio Grande do Sul Meridional. Pelotas: Embrapa Clima Temperado, 2007. 26p.

STUMPF, E.R.T.; FISCHER, S.Z.; BARBIERI, R.L.; HEIDEN, G.; NEITZKE R.S.; GROLLI, P.R. Uso de folhagens de corte no sul do Rio Grande do Sul. Revista
Brasileira de Agrociência, Pelotas, v.14, n.2, p.249-258, 2008.

TSEGAW, T.; TILAHUN, S.; HUMPHRIES, G. Influence of pulsing biocides and preservative solution treatment on the vase life of cut rose (Rosa hybrida L.) varieties. Ethiopian Journal of Applied Sciences and Technology, Addis Abeba, v.2, n.2, p.1-18, 2011. 
